\title{
Near-infrared autofluorescence in thyroid and parathyroid surgery
}

\author{
Aimee N. Di Marco ${ }^{1,2}$, Fausto F. Palazzo ${ }^{1,2}$ \\ ${ }^{1}$ Department of Endocrine Surgery, Hammersmith Hospital, Imperial College Healthcare NHS Trust, London, UK; ${ }^{2}$ Department of Surgery \& \\ Cancer, Imperial College, London, UK \\ Contributions: (I) Conception and design: FF Palazzo; (II) Administrative support: AN Di Marco; (III) Provision of study materials or patients: All \\ authors; (IV) Collection and assembly of data: All authors; (V) Data analysis and interpretation: All authors; (VI) Manuscript writing: All authors; (VII) \\ Final approval of manuscript: All authors. \\ Correspondence to: Miss Aimee N. Di Marco. Department of Endocrine Surgery, Hammersmith Hospital, Imperial College Healthcare NHS Trust, \\ Du Cane Road, London W12 0HS, UK. Email: a.di-marco@imperial.ac.uk.
}

\begin{abstract}
Contrast-free autofluorescence (AF) of the parathyroid glands (PTGs) and thyroid tissue occurs in the near-infrared (NIR) spectrum on excitation by light in the upper range of the visible spectrum or lower NIR spectrum. In vivo, PTGs autofluoresce more brightly than thyroid (by a factor of 2-20 times) and appear as a bright spot against surrounding thyroid, muscle or fat on a processed image which is generated in real-time. NIR-AF of PTGs was first described in 2009 although NIR-AF had previously been used in several other clinical applications. Since then there has been a great amount of interest in the use of NIR-AF in thyroid and parathyroid surgery with over 25 published reports of the utilisation of both self-built and proprietary NIR-AF devices in neck endocrine surgery. All of these reports have confirmed the feasibility of NIR-AF intraoperatively and its ability to detect PTGs, although the reported accuracy varies from $90-100 \%$. Reports of the effect of NIR-AF on relevant clinical endpoints i.e., post-operative hypoparathyroidism in thyroidectomy and persistent disease in parathyroidectomy are however scant. There has been one multicentre clinical trial of NIR-AF in thyroidectomy but this did not report clinical outcomes and two single-centre, non-randomised studies which did report post-operative hypoparathyroidism but with differing results: one showing no benefit in 106 NIR-AF $v s .163$ controls and one, a reduction of early hypocalcaemia from $20 \%$ to $5 \%$ in 93 NIR-AF patients vs. 420 controls. There were only 2 cases of permanent hypoparathyroidism across both studies and therefore no significant observable difference in this key outcome variable. In parathyroidectomy, possible variability of the AF signal due to composition of a PTG adenoma, secondary/tertiary disease and MEN1 as well as depth-penetration preventing detection of sub-surface PTGs would imply that NIR-AF in its current form is not well-placed to improve curerates in hyperparathyroidism, which may already be as high as $98 \%$. Thus far, no study has addressed this. Despite the promising results of NIR-AF, the absence of data demonstrating an improvement in outcomes and the cost of its use currently limit its use in routine clinical practice, especially in a publicly funded healthcare system with budgetary constraints. However, it can be utilised in research settings and this should be undertaken within the context of well-designed and conducted randomised, multi-centre, appropriately powered studies, which will assist in establishing its role in neck endocrine surgery.
\end{abstract}

Keywords: Near-infrared autofluorescence (NIR-AF); parathyroid glands (PTGs); hypoparathyroidism; thyroid surgery

Submitted Oct 20, 2019. Accepted for publication Jan 14, 2020.

doi: 10.21037 /gs.2020.01.04

View this article at: http://dx.doi.org/10.21037/gs.2020.01.04 


\section{Introduction}

\section{Background}

Surgery of the thyroid and parathyroid glands (PTGs) has evolved considerably since the emergence of endocrine surgery as a specialty in the 1970s (1). Improvements in our understanding of the underlying disease processes, surgical anatomy and the collection of patient outcome data have informed the refinement of surgical techniques and dramatically enhanced results.

Thyroidectomy surgical technique is designed to minimize the risk of injury to the recurrent and superior laryngeal nerves and to the PTGs while effectively treating the pathology. Preservation of the PTGs in situ requires early identification and preservation of their vascular pedicles using careful capsular dissection and the avoidance of excessive manipulation and exposure of the glands to thermal energy. However, even with meticulous surgical technique, PTGs may be rendered non-viable or inadvertently removed. If a nonviable parathyroid is recognised during surgery, autotransplantation may be undertaken: in this simple technique, parathyroid tissue is morcellated, suspended in a balanced salt solution and injected into the sternocleidomastoid muscle. When performed correctly this appears to reduce the incidence of post-operative hypoparathyroidism $(2,3)$.

Parathyroidectomy consists in the identification of the PTGs and the removal of those responsible for the biochemical abnormality, curing the hyperparathyroidism, without the irreversible damage or removal of normally functioning PTGs that could result in hypoparathyroidism. At present, this relies upon the judgement and experience of the surgeon (4) and although excellent cure rates of up to $98 \%$ may be achieved in the best centres (5), there is considerable cost and morbidity associated with failure to cure and reoperations $(6,7)$.

Technological adjuncts to permit the recognition and viability of PTGs are therefore a very attractive proposition in both thyroid and parathyroid surgery.

\section{Autofluorescence (AF)}

$\mathrm{AF}$ is the emission of light by a naturally-occurring fluorophore, on excitation by incident light of a specific wavelength (8). The term AF distinguishes the fluorescence produced by an endogenous fluorophore from that resulting from the application of a synthetic fluorescent marker such as indocyanine green (ICG). Several human tissues exhibit the property of AF, examples of commonly encountered fluorophores being NADPH, the flavins, collagen, elastin and cholecalciferol. Each fluorophore emits AF of a specific wavelength with the majority of biological substrates having a peak signal intensity below $800 \mathrm{~nm}$, i.e., in the UV and visible light range.

The property of $\mathrm{AF}$ in a tissue therefore varies depending on the presence of a fluorophore/fluorophores, their concentration and the wavelength at which they emit AF. Consequently, tissue AF may be affected by pathological changes and it has therefore been exploited in a number of medical applications including dermatology, ophthalmology and oncological surgery (9-11).

$\mathrm{AF}$ is one of a range of techniques known as 'optical biopsy', a term coined to describe the fact that pathological information may be deduced without physically excising tissue.

\section{History}

'Native fluorescence' was first described in the early 1800 s by Sir David Brewster in Edinburgh and the term 'Autofluorescence' (AF) used subsequently by George Gabriel Stokes in Cambridge. Stokes also gave his name to the phenomenon whereby the wavelength of light emitted by a given tissue differs from that of the exciting light: 'the Stokes shift'. This property is seen in both Raman spectroscopy and AF (12). The use of 'optical biopsy' in parathyroid tissue was first described in 2006 by Das et al. (13) who used Raman spectroscopy with an incident wavelength of $830 \mathrm{~nm}$ to excite 15 ex vivo PTGs and found a significant difference in the resultant signals emitted by adenomata and hyperplastic glands. However, the wavelength of the incident light used was such that the peak emission of parathyroid tissue was missed. This was subsequently discovered by a group from Vanderbilt University (14).

\section{AF of parathyroid and thyroid tissue}

The Vanderbilt group studied AF from parathyroid, thyroid and other surrounding tissues generated by excitation at a range of spectra and established that excitation by light of $785 \mathrm{~nm}$ reliably produced the maximal emission from both thyroid and parathyroid tissue. This occurs at $820-830 \mathrm{~nm}$, i.e., in the near-infrared (NIR) spectrum (14). The same group performed the first in vivo study of 21 patients with a range of pathologies undergoing neck endocrine surgery 


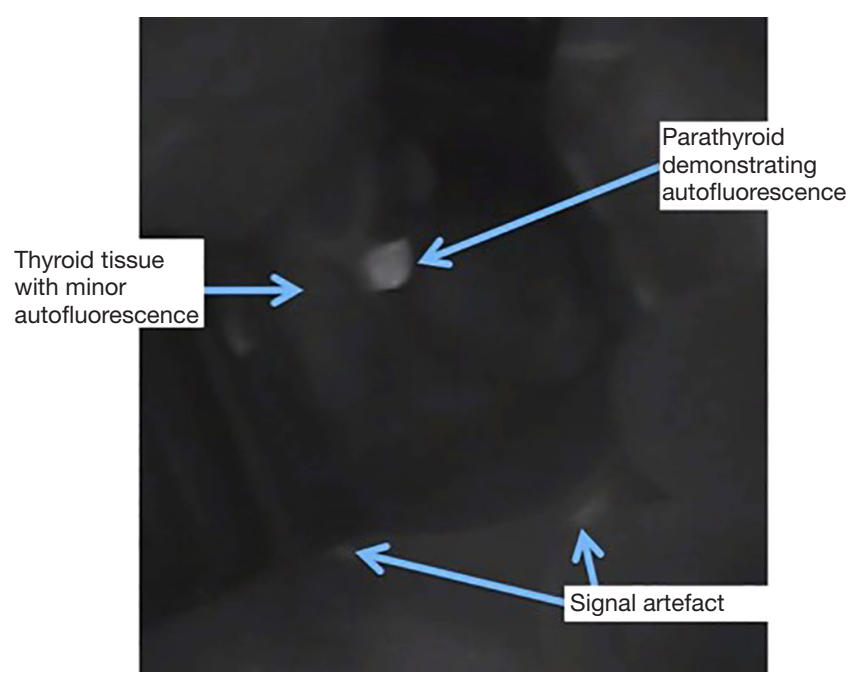

Figure 1 NIR fluorescent imaging performed during thyroidectomy. Image showing the right thyroid lobe retracted medially with intense fluorescence of the right superior parathyroid gland, minor background fluorescence from the thyroid and some artefact from surgical marker pen on the skin. NIR, near-infrared.

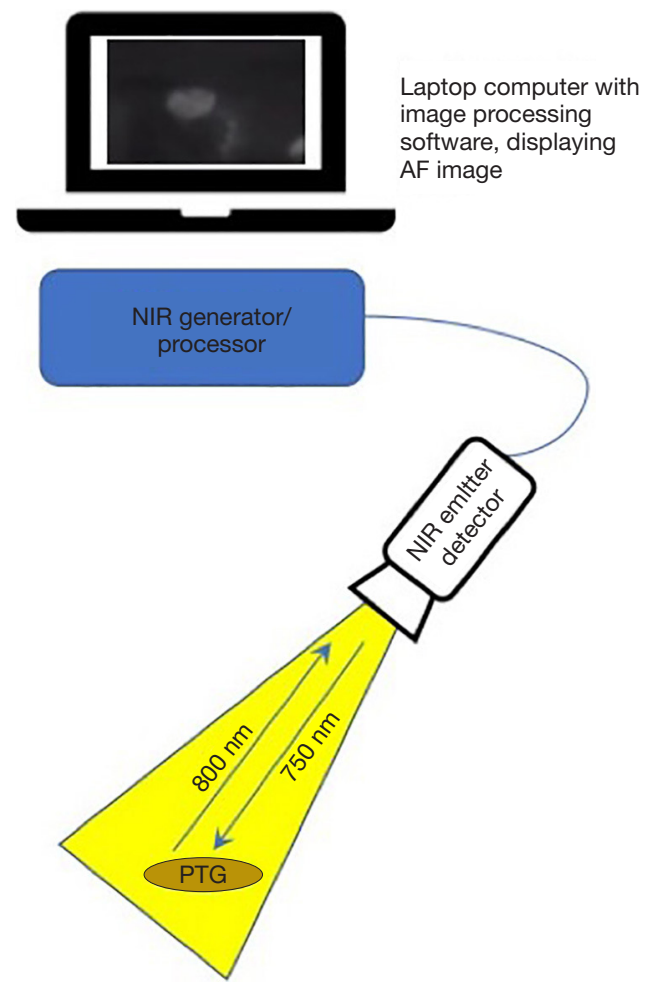

Figure 2 Example of a NIR-AF system showing a NIR emitter (750-800 nm wavelength), detector (optimised to 800-830 $\mathrm{nm}$ ), processor and visual display. NIR-AF, near-infrared autofluorescence. and found that while the peak emission from both thyroid and parathyroid occurred at the same NIR wavelength, parathyroid tissue AF intensity was two to eleven times greater than that of thyroid (15). In practise this gives the appearance, when viewed using a NIR emitter-detector, of a bright white spot (the PTG) on a background of a lowgrade fluorescence (thyroid) (see Figure 1). PTG AF has been shown to continue for at least one hour ex vivo (16).

While several fluorophores responsible for the AF of PTGs have been proposed, to date, none have been proven. Porphyrins produce the most durable fluorescence in biological tissue but have a peak emission of $600-700 \mathrm{~nm}$, i.e., significantly lower than that of PTGs (14). Melanin is known to be the primary fluorophore in skin but is not found in PTGs or thyroid tissue $(17,18)$. The calciumsensing receptor has been suggested as the fluorophore in thyroid and PTG due to its presence in both and higher concentration in PTGs. However, this has not been demonstrated conclusively (15).

\section{NIR-AF devices}

Devices for AF imaging of the PTGs consist of an emitter of light of around 750-800 nm, i.e., in the lower end of the NIR spectrum, a detector which is optimised to NIR light of 800-830 nm, a processor and a visual display (see Figure 2). Mahadevan-Jansen's Vanderbilt group developed their device in the laboratory and subsequently compared its performance to a clinical prototype which has now received regulatory approval and is known as the PT-Eye (19). Their original device consists of a spectrometer, a $785 \mathrm{~nm}$ diode laser, custom-made fibreoptic probe and laptop computer. Simultaneous emission by the laser and detection by the probe is processed by LabView software on the laptop and an image produced. The probe may be sterilised with ethylene oxide or Sterrad and reused. Serra et al. describe the use of a $780 \mathrm{~nm}$ light-emitting diode to generate $\mathrm{AF}$ and night-vision goggles with an $835 \mathrm{~nm}$ NIR filter for visualisation. This set-up was tested in a pilot study of five patients undergoing surgery for primary hyperparathyroidism (20). A Korean group have also reported their experience in 3 patients with an inexpensive lab-built device, the 'raspberry Pi' which uses a $785 \mathrm{~nm}$ laser diode and filter to detect NIR-AF at a wavelength over $808 \mathrm{~nm}(21)$.

There are several commercially available NIR-AF devices suitable for neck endocrine surgery; the most commonly utilised being those by Fluoptics, Karl Storz and Stryker 
Table 1 Commercially-available devices for NIR-AF

\begin{tabular}{|c|c|c|c|c|}
\hline Device & Manufacturer & NIR-AF +/- ICG & $\begin{array}{l}\text { Open/laparoscopic } \\
\text { camera head }\end{array}$ & Camera/processor \\
\hline Fluobeam 800 & Fluoptics, Grenoble, France & Optimised for AF & Open & $\begin{array}{l}750 \mathrm{~nm} \text { laser excitation/800 nm detector/Fluosoft } \\
\text { software processor }\end{array}$ \\
\hline FluobeamLX & Fluoptics, Grenoble, France & AF + ICG setting & Open & $\begin{array}{l}750 \mathrm{~nm} \text { laser excitation/800 } \mathrm{nm} \text { detector/Fluosoft } \\
\text { software processor }\end{array}$ \\
\hline PINPOINT $^{\circledR}$ & $\begin{array}{l}\text { Stryker (previously Novadaq, } \\
\text { Ontario, Canada) }\end{array}$ & $A F+I C G$ setting & $\begin{array}{l}\text { Open and laparoscopic } \\
\text { versions }\end{array}$ & Emission at $805 \mathrm{~nm} /$ detection at $830 \mathrm{~nm}$ \\
\hline PT-Eye & Vanderbilt University & AF only & Open & $785 \mathrm{~nm}$ fibreoptic probe/820 $\mathrm{nm}$ receiver \\
\hline
\end{tabular}

NIR-AF, near-infrared autofluorescence; ICG, indocyanine green.

(previously Novadaq) as listed in Table 1. Differences between the systems are: the exact wavelength emitted and detected, the source of the emitted light (xenon or laser), type of handpiece provided, i.e., suited for open surgery or laparoscopy and the type of display used. Some systems are optimised for label-free true AF detection whereas others focus on imaging with a contrast tracer, i.e., ICG or offer both. All systems depend on minimising the ambient light such that all background lights must be extinguished, and all provide real-time images in a matter of moments. The ability of NIR light to penetrate tissue is limited to a depth of 2-3 mm maximum and so all systems have a similar capacity to display subsurface structures. Nearly all of the commercially-available systems are contact-free, i.e., the camera head is simply held over the tissue, although the PT-Eye which received FDA approval in late 2018 (22) and CE marking more recently, does require contact between its probe tip and the tissue. This device was developed by the Mahadevan-Jansen group at Vanderbilt University from their laboratory device, its distinguishing features being an internal micro-processor board instead of an external laptop, the housing of the laser source and detector within a single casing and a foot-pedal for activation (19).

\section{Method for using NIR-AF}

The majority of NIR-AF devices suitable for neck endocrine surgery have similar characteristics and are deployed in a similar manner. Our group has reported experience using the Fluobeam 800 (Fluoptics, Grenoble, France) in 365 patients (96 parathyroids and 269 thyroids) $(23,24)$. The camera head is connected to the Fluobeam processor which is in turn connected to a laptop which houses the Fluosoft software and displays the image on its screen. The camera head is placed in a sterile sheath and kept on a sterile trolley until the surgeon is ready to use it. The surgeon undertakes the operation as standard until, in thyroidectomy, the lobe is mobilised or in parathyroidectomy when dissection to the pre-vertebral fascia with exposure of relevant structures has been performed. The NIR-AF camera head within its sterile sheath is then held over the operating field at a distance of around $20 \mathrm{~cm}$ and perpendicular to the target area to be visualised. The operating lights and all background lights must then be extinguished and any ambient light excluded. The images generated are displayed on the screen so the surgeon must correlate the operative findings with that seen on the screen. In thyroidectomy the NIR-AF is used to confirm and/or identify PTGs preserved in the thyroid bed and check for any parathyroid tissue on the lobe which needs to be released and preserved. After excision of the lobe the NIR-AF is applied again to search for any inadvertently removed parathyroid tissue which is then autotransplanted (24). In parathyroidectomy the NIRAF may be deployed to assist in confirmation of PTGs and/ or to assist in identifying any glands which are not apparent on conventional inspection. It should however be noted that pathological PTGs may not reliably autofluoresce and that due to the limited depth penetration of NIR-AF, PTGs more than a couple of millimetres beneath the surface may be missed. The addition of NIR-AF to each operation takes only a few minutes.

The other commercially available devices are all used in the same manner with the exception of the PT-Eye which requires gentle contact between the probe tip and tissue 
being visualised (19).

\section{Use of contrast tracer}

ICG is a contrast agent which emits its maximal NIR-AF at around $830-835 \mathrm{~nm}$ when excited at $780-805 \mathrm{~nm}(25,26)$. It is an amphiphilic tricarbocyanine dye which may be administered intravenously, whereupon it travels within the circulation and is visualised using a NIR emitter-detector in the same way as AF from biological tissue is generated. The half-life is $3-5$ minutes and the tracer is excreted by the biliary system in approximately 15-20 minutes (27). The recommended dose for visualisation is $0.2-0.5 \mathrm{mg} / \mathrm{kg}$, which may be repeated as required without exceeding the maximal daily dose of $5 \mathrm{mg} / \mathrm{kg}(27,28)$. There is a potential, though rare, non-dose-related, risk of inducing anaphylaxis, a reaction which is not reliably predicted by tolerance of iodinated contrast. Using a NIR emitter-detector placed over the exposed PTGs and following injection of ICG, the arterial supply and venous drainage of PTGs may be observed, along with their colour, which varies depending on their absorption of the ICG (29). Based on these observations it is proposed that a judgement may be made as to the viability of that parathyroid gland, allowing autotransplantation of non-viable glands $(28,30,31)$. The procedure is generally quick to perform and proponents cite reduced rates of hypoparathyroidism following thyroidectomy $(29,32)$.

\section{Discussion}

Contrast-free AF is a low-risk tool which is easy and quick to use intra-operatively and, in the experience of the authors, takes little time and creates very minimal disruption to the operative workflow. However, there is a learning-curve before optimal images are achieved: the surgeon must establish the most appropriate distance between the camera and subject, acquaint themselves with the timing of switching off theatre and background lights while keeping the position of the presumed PTG in the operative field marked for correlation. It is also necessary to establish through experience the depth at which tissue can be visualised successfully. The duration of and nature this learning-curve has not been studied.

All studies performed on AF in neck endocrine surgery have confirmed its feasibility using a variety of different AF devices and demonstrated the ability of NIR-AF to elicit a signal from $90-100 \%$ of PTGs (see Table 2). However, when considering its true utility, one must establish the clinical problem that needs to be overcome with this technology and therefore how best to design studies which truly test the ability of NIR-AF to achieve the desired outcome.

\section{NIR-AF in thyroidectomy}

In thyroidectomy the problem to be solved is permanent post-operative hypoparathyroidism, defined as the longterm dependence on calcium and vitamin-D analogues. Patients with permanent hypoparathyroidism have been shown to have a poorer quality of life than an equivalent non-hypoparathyroid post-thyroidectomy cohort (43) and in at least one study an increase in mortality has been reported (44). The reported incidence of permanent hypoparathyroidism after total thyroidectomy ranges from $1 \%$ to $25 \%(3,45,46)$. The mechanisms which contribute to the loss of parathyroid function are: (I) inadvertent removal, (II) damage to arterial supply and/or venous drainage, (III) direct injury from manipulation or thermal energy, or a combination of these. With this is mind, it is logical that a tool which permits early and confident identification of PTGs may prevent hypoparathyroidism induced by any of these mechanisms. However, NIR-AF alone cannot confirm viability of PTGs left in-situ since AF persists after devascularisation or inadvertent removal. The confirmation of vascular integrity is more likely to require a tracer such as ICG. One head-to-head study of contrast-free AF and ICG exists and this only compared the ability of the two methods to demonstrate the presence of PTGs. Interestingly, NIR$\mathrm{AF}$ was found to have a tendency to greater accuracy than ICG, although the difference did not reach statistical significance $(98 \%$ vs. $95 \% \mathrm{P}=0.31)$ and a greater ability to demonstrate PTGs before surgeon-identification (AF 52\% vs. ICG 6\% $\mathrm{P}<0.001)(37)$.

The study of AF in thyroidectomy is complicated by the fact that the gold-standard for comparison of identification of PTGs is the surgeon's eyes i.e., we are testing a device designed to augment surgical judgement against that as a benchmark. Nonetheless, this is clearly the most appropriate method, with biopsy of normal tissue posing an unnecessary risk to the patient. Several studies have tried to establish whether NIR-AF allows identification before the surgeon. This is another difficult and subjective question to study and results have been mixed: Kose et al. showed identification prior to the surgeon of only $23 \%$ (33) whereas the same group reported $37-67 \%$ in a multicentre study (36) and a median number of 2 PTGs identified with NIR-AF 
Table 2 Published studies using AF (without ICG) in vivo for thyroidectomy and parathyroidectomy

\begin{tabular}{|c|c|c|c|c|}
\hline Reference & Device used & Study group & Study question & Result \\
\hline $\begin{array}{l}\text { Kose et al. } \\
2019 \text { (33) }\end{array}$ & Fluobeam800 & $\begin{array}{l}310 \text { patients: } 173 \text { thyroidectomy } \\
\& 137 \text { parathyroidectomy }\end{array}$ & $\begin{array}{l}\text { Do PTGs reliably show AF and is } \\
\text { AF more sensitive than surgeon } \\
\text { identification? }\end{array}$ & $\begin{array}{l}98 \% \text { PTGs AF but only } 23 \% \\
\text { identified before the surgeon }\end{array}$ \\
\hline $\begin{array}{l}\text { Thomas et al. } \\
2019 \text { (34) }\end{array}$ & $\begin{array}{l}\text { PT-Eye +/- overlay } \\
\text { imaging (OTIS) }\end{array}$ & $\begin{array}{l}41 \text { patients thyroidectomy \& } \\
\text { parathyroidectomy }\end{array}$ & $\begin{array}{l}\text { Sensitivity of AF for PTG- } \\
\text { pathological and normal/added } \\
\text { value of OTIS }\end{array}$ & $\begin{array}{l}98 \% \text { PTG AF, no difference for } \\
\text { normal vs. pathological tissue. } \\
\text { Enhanced sensitivity with OTIS } \\
(98 \% \text { vs. } 100 \%)\end{array}$ \\
\hline $\begin{array}{l}\text { Kim et al. } \\
2018(21)\end{array}$ & Raspberry-Pi & $\begin{array}{l}\text { Pilot study of lab-built } \\
\text { device } 3 \text { patients undergoing } \\
\text { thyroidectomy }\end{array}$ & Feasibility/accuracy & $\begin{array}{l}100 \% \text { accuracy of PTG } \\
\text { identification }\end{array}$ \\
\hline $\begin{array}{l}\text { Kahramangil } \\
\text { et al. } 2018 \text { (36) }\end{array}$ & Fluobeam800 & $\begin{array}{l}\text { Multicentre study of } \\
210 \text { patients thyroidectomy \& } \\
\text { parathyroidectomy }\end{array}$ & $\begin{array}{l}\text { Accuracy for AF and ability to } \\
\text { detect before the surgeon }\end{array}$ & $\begin{array}{l}98 \% \text { accuracy/detection before } \\
\text { the surgeon in } 37-67 \% \text { cases }\end{array}$ \\
\hline $\begin{array}{l}\text { Kahramangil } \\
\text { et al. } 2017 \text { (37) }\end{array}$ & $\begin{array}{l}\text { Fluobeam for AF/ } \\
\text { Pinpoint for ICG }\end{array}$ & $\begin{array}{l}44 \text { patients thyroidectomy: } \\
22 \text { AF vs. } 22 \text { ICG }\end{array}$ & $\begin{array}{l}\text { Comparison of accuracy and ability } \\
\text { to detect before the surgeon }\end{array}$ & $\begin{array}{l}\text { Accuracy } 98 \% \text { vs. } 95 \% \text {. Early } \\
\text { detection with AF }\end{array}$ \\
\hline $\begin{array}{l}\text { Ladurner et al. } \\
2018 \text { (40) }\end{array}$ & Karl Storz & $\begin{array}{l}41 \text { PTGs in } 20 \text { patients } \\
\text { undergoing thyroidectomy }\end{array}$ & Ability of AF to identify PTGs & $37 / 41$ accuracy $(90.2 \%)$ \\
\hline $\begin{array}{l}\text { Kim et al. } \\
2016(41)\end{array}$ & $\begin{array}{l}\text { Group's own lab } \\
\text { device }\end{array}$ & $\begin{array}{l}8 \text { patients } / 16 \text { PTGs. } \\
\text { Thyroidectomy for PTC }\end{array}$ & $\begin{array}{l}\text { Feasibility of AF for PTG } \\
\text { identification }\end{array}$ & $100 \%$ positive predictive value \\
\hline $\begin{array}{l}\text { McWade et al. } \\
2016 \text { (42) }\end{array}$ & $\begin{array}{l}\text { Group's own lab } \\
\text { device }\end{array}$ & 137 patients/264 glands & $\begin{array}{l}\text { Accuracy of PTG identification/ } \\
\text { clinical factors affecting AF }\end{array}$ & $\begin{array}{l}\text { 97\% accuracy of PTG } \\
\text { identification. AF correlation with } \\
\text { BMI, serum Ca, serum vitamin D. } \\
\text { Secondary HPT confounder }\end{array}$ \\
\hline
\end{tabular}

NIR-AF, near-infrared autofluorescence; ICG, indocyanine green; PTGs, parathyroid glands; PTC, papillary thyroid carcinoma; HPT, hyperparathyroidism.

before surgeon visualisation with at least one PTG seen before the surgeon in $82 \%$ (37) in another study.

The sensitivity and accuracy of NIR-AF for PTGs has been reported as between $90 \%$ and $98 \%$. Ladurner reported a sensitivity of $90 \%$ in 20 thyroidectomies using a Karl Storz system whereas 3 groups have reported rates of $98 \%$ in larger studies $(33,34,36)$ including the only multicentre study published. The true sensitivity and 

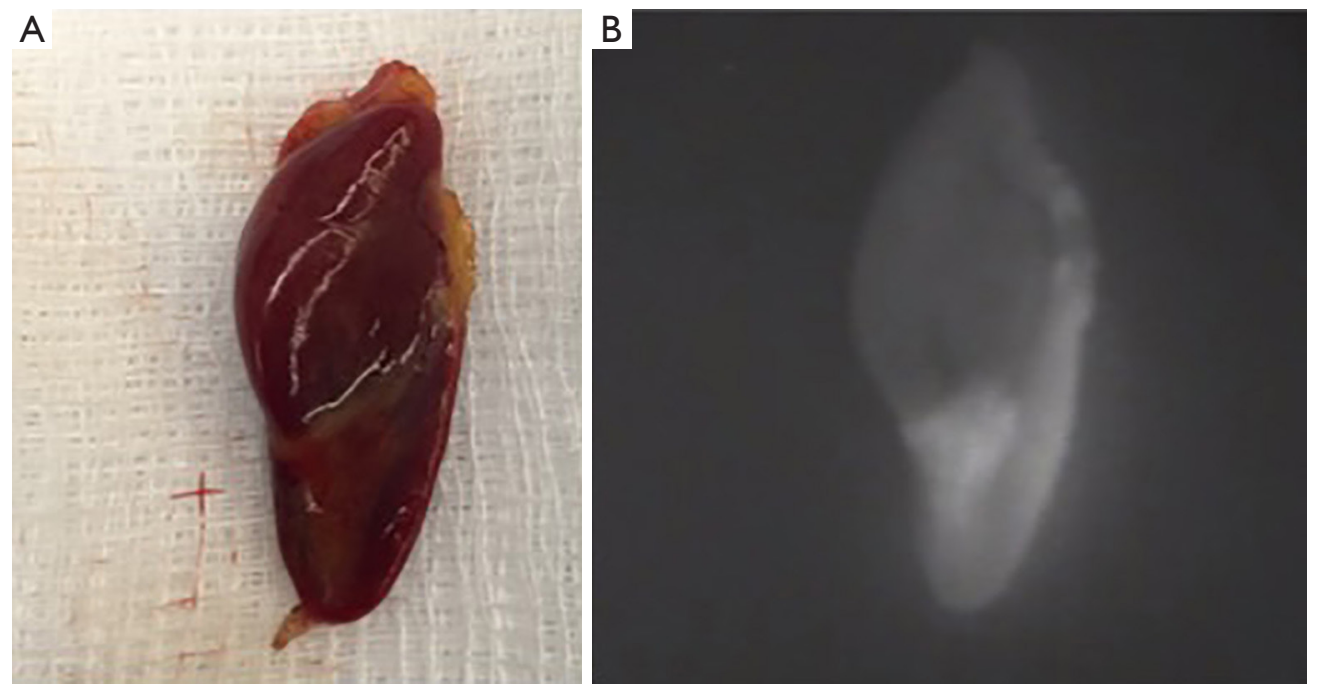

Figure 3 Ex vivo image of a parathyroid adenoma taken shortly after excision showing mixed autofluorescence with a rim of intense signal (the compressed normal parathyroid tissue) and adenoma with no signal emission.

accuracy obviously impact upon what the real clinical value of NIR-AF may be given that in a centre with low rates of permanent hypoparathyroidism, i.e., 1-2\%, identification of $90 \%$ of PTGs by NIR-AF is unlikely to provide a clinical improvement. Perhaps the most appropriate study design now that technical comparisons of surgeonidentification $v s$. NIR-AF for PTGs as a surrogate for the sensitivity or accuracy of NIR-AF have been shown, is the rate of post-operative hypoparathyroidism with and without NIR-AF. Only a handful of studies have addressed this and results have been mixed: our own group compared early post-operative serum calcium and parathyroid hormone (PTH) measurements in patients undergoing total thyroidectomy with NIR-AF compared to a group of thyroidectomies pre-dating the introduction of NIR-AF to our department. We found hypocalcaemia on day 1 in $10.5 \%(n=9)$ controls and $9.3 \%(n=5)$ in the NIR-AF group $(\mathrm{P}=0.53)$, hypoparathyroidism at day 1 in $11.6 \%(\mathrm{n}=10)$ and $11.1 \%(\mathrm{n}=6)(\mathrm{P}=0.38)$ and no cases of hypoparathyroidism at beyond 6 months postthyroidectomy in either group. A larger and also nonrandomised study of 513 total thyroidectomies compared 93 NIR-AF patients to 420 non-NIR-AF patients in 3 control groups and demonstrated a significant reduction in hypocalcaemia on day 1 at $5.2 \%$ vs. $20.9 \%(\mathrm{P}<0.001)$. There were only 2 cases of hypoparathyroidism at over 6 months and both occurred in the control patients.

Despite these studies having contradictory results regarding early hypocalcaemia, both show no demonstrable benefit in the prevention of persistent hypoparathyroidism. Randomised and powered studies are required to establish this with certainty: assuming a rate of permanent hypoparathyroidism of $2 \%$ vs. $0.5 \%$ with NIR-AF, a power of 0.8 and significance of 0.05 , a total of 1,720 patients (860 per group) would need to be recruited to generate a statistically meaningful result.

\section{NIR-AF in parathyroidectomy}

In parathyroidectomy the clinical problem to be addressed is failure to cure the hyperparathyroidism due to a missed adenoma or unrecognised multiple gland disease. The rate of failure to cure may be as low as $2 \%$ in specialist centres (5). While several studies have shown that AF may identify PTGs before the surgeon $(33,36,37)$ and may detect missed parathyroids on thyroid specimens (24), to the knowledge of the authors, none have compared cure rates with and without the use of NIR-AF in parathyroidectomy.

Potential pitfalls in NIR-AF for parathyroidectomy include the variable fluorescence of PTGs, glands concealed beneath the surface, ectopic glands and genetic disease. Non-pathological parathyroid tissue has been shown to autofluoresce brightly and reliably, whereas pathological PTGs have been shown to emit variable AF with some showing mixed high and low signal (Figure 3) and others being uniformly dark. PTGs of patients with secondary 
HPT have been shown to be particularly variable in their AF. However, not all groups have found that pathology in the PTG reduced detection rates with NIR-AF: in a small study of 41 mixed patients, Thomas et al. showed no significant difference with an overall detection rate of $98 \%$ (34). Due to the limitations of depth penetration of NIR-AF, PTGs concealed even at a depth of 2-3 mm may be missed. In the case of ectopic glands, the limited penetration of NIR-AF will also prevent their detection.

Phay's group have studied AF in patients with Multiple Endocrine Neoplasia Type 1 undergoing parathyroidectomy for primary hyperparathyroidism and reported decreased $\mathrm{AF}$ of the PTGs and increased background AF causing significantly elevated rates of false negative and false positives in this subset of patients (47). Unrecognised MEN1 and secondary/tertiary HPT in patients undergoing parathyroidectomy may therefore present a source of error for NIR-AF.

A fully powered and randomised study with cure rates of hyperparathyroidism in matched patients as the primary outcome measure is required. Assuming a failure-tocure rate of $2 \%$ background and improvement to $0.1 \%$, 902 patients would need to be studied (451 in each group).

\section{Cost-effectiveness}

The various commercially available systems require significant initial outlay costs unless, for example, there is already a compatible laparoscopic stack system in situ (such as the Karl Storz) which may only require the addition of a new camera head for NIR-AF imaging. The device used by the authors in 2019 costs approximately $£ 35,000$ (c. $\$ 44,000)$ for the full system plus consumables for one year (sterile sheaths being priced at $£ 40 \approx \$ 50$ ). The capital and ongoing running costs must be set against the number of patients imaged using NIR-AF and any costsaving made by the prevention of hypoparathyroidism/ persistent hyperparathyroidism. The true cost-effectiveness can therefore not be calculated until any clinical benefit has been proven. Thus far, a reduction in temporary hypoparathyroidism has been demonstrated by one large study (39). If this does prove to be correct and given the cost of 1 month of hypoparathyroidism is approximately $£ 250$ (covering oral calcium and calcitriol plus monthly blood tests and physician visits) per patient in the UK. The number of months of temporary hypoparathyroidism required to offset the cost of the system used by the authors would be 140 per annum. The authors found their rate of early post-operative hypoparathyroidism (i.e., recovered within 1 month) to be $10 \%$ whereas Benmiloud reported $60-70 \%$. In the author's practice, 1,400 total thyroidectomies would therefore need to be performed per annum to become cost neutral, or in Benmiloud's cohort, approximately 215 total thyroidectomies would be required. Nonetheless, these calculations are hypothetical and subject to many variables such that only a large-scale randomised trial of total thyroidectomy with and without NIR-AF would be required before any cost analysis can be performed with accuracy. The cost-benefit in parathyroidectomy is even harder to estimate as the cost of failure is so variable depending on whether the patient is reinvestigated and undergoes reoperation and whether they are cured at that juncture.

\section{Future developments}

Further developments in NIR-AF technology may also affect its real-life clinical utility. Probe-based imaging (the PTEye) as opposed to a non-contact camera has been developed by the Vanderbilt University group and shown to be equally accurate when compared to non-contact imaging. However, it has the benefit of circumventing the reduction in image-quality caused by ambient light and of producing a quantitative output of NIR-AF $(34,35)$. The 'PTEye' could theoretically be used in a similar manner to the nerve monitor: placed on tissue, with a sound being generated once a threshold for AF had been crossed. Or, drawn across tissue waiting for the sound to signal PTG concealed beneath the surface.

The same group have also tried to overcome the need of the surgeon to correlate the operative field with the AF image seen on screen. They report the development and use of the 'OTIS': Intraoperative tissue imaging overlay system which maps and projects the $\mathrm{AF}$ onto the operative field such that the surgeon need not look away to a separate screen. In 30 thyroid/parathyroidectomies the accuracy of this system was reported as being as high as $97 \%$ (34).

\section{Conclusions}

The ability of NIR-AF to demonstrate PTGs with accuracy intraoperatively is extremely promising. This ability seems to be universal across the various laboratory-built and proprietary devices available although variability of $90-100 \%$ has been demonstrated. The technology is low risk given that is requires no contrast, no change to the 
operative workflow and involves no harmful radiation of tissues. There is however a significant cost involved to in purchase, maintenance and single-use consumables. Despite several studies showing the feasibility and efficacy of PTG identification by NIR-AF, only 2 have addressed the postoperative outcome of hypoparathyroidism following thyroidectomy and results have been discordant. In parathyroidectomy, no study has been performed to evaluate the effect on cure rates. Therefore, in the opinion of the authors, appropriately powered and randomised studies in both operations are required to determine whether the use of NIR-AF will add to real world clinical practice. Given the fast-evolving nature of the technology and potential clinical impact, such studies should be pursued.

\section{Acknowledgments}

None.

\section{Footnote}

Conflicts of Interest: The authors have no conflicts of interest to declare.

Ethical Statement: The authors are accountable for all aspects of the work in ensuring that questions related to the accuracy or integrity of any part of the work are appropriately investigated and resolved.

\section{References}

1. Zeiger M, Shen WT, Felger EA. The Supreme Triumph of the Surgeon's Art': A Narrative History of Endocrine Surgery. Berkeley, Los Angeles, London: University of California Medical Humanities Press; 2013.

2. Palazzo FF, Sywak MS, Sidhu SB, et al. Parathyroid autotransplantation during total thyroidectomy - Does the number of glands transplanted affect outcome? World J Surg 2005;29:629-31.

3. Christakis I, Constantinides VA, Tolley NS, et al. Parathyroid Autotransplantation during thyroid surgery. World J Endocr Surg 2012;4:115-7.

4. Stavrakis AI, Ituarte PHG, Ko CY, et al. Surgeon volume as a predictor of outcomes in inpatient and outpatient endocrine surgery. Surgery 2007;142:887-99.

5. Norlén O, Wang KC, Tay YK, et al. No Need to Abandon Focused Parathyroidectomy: A Multicenter Study of Long-term Outcome after Surgery for Primary
Hyperparathyroidism. Ann Surg 2015;261:991-6.

6. McIntyre CJ, Allen JLY, Constantinides VA, et al. Patterns of Disease in Patients at a Tertiary Referral Centre Requiring Reoperative Parathyroidectomy. Ann R Coll Surg Engl 2015;97:598-602.

7. Chadwick D, Kinsman R, Walton P. The British Association of Endocrine \& Thyroid Surgeons. Fifth National Audit Report. Oxford: Dendrite Clinical Systems Ltd; 2017. Available online: https://www.baets.org.uk/wpcontent/uploads/BAETS-Audit-National-Report-2017.pdf

8. Croce AC, Bottiroli G. Autofluorescence spectroscopy and imaging: a tool for biomedical research and diagnosis. Eur J Histochem 2014;58:2461.

9. Meerwaldt R, Lutgers HL, Links TP, et al. Skin autofluorescence is a strong predictor of cardiac mortality in diabetes. Diabetes Care 2007;30:107-12.

10. Tanaka K, Tani Y, Asai J, et al. Skin autofluorescence is associated with severity of vascular complications in Japanese patients with Type 2 diabetes. Diabet Med 2012;29:492-500.

11. Keller MD, Majumder SK, Kelley MC, et al. Autofluorescence and diffuse reflectance spectroscopy and spectral imaging for breast surgical margin analysis. Lasers Surg Med 2010;42:15-23.

12. Gispert J. Coordination Chemistry. Wiley; 2008:483.

13. Das K, Stone N, Kendall C, et al. Raman spectroscopy of parathyroid tissue pathology. Lasers Med Sci 2006;21:192-7.

14. Paras C, Keller M, White L, et al. Optical guidance of endocrine surgery. In: SPIE Photonics: Unpublished conference proceedings. Bellingham, WA, USA; 2009:7159-69.

15. Paras C, Keller M, White L, et al. Near-infrared autofluorescence for the detection of parathyroid glands. J Biomed Opt 2011;16:067012.

16. De Leeuw F, Breuskin I, Abbaci M, et al. Intraoperative Near-infrared Imaging for Parathyroid Gland Identification by Auto-fluorescence: A Feasibility Study. World J Surg 2016;40:2131-8.

17. Han X, Lui H, McLean DI, et al. Near-infrared autofluorescence imaging of cutaneous melanins and human skin in vivo. J Biomed Opt 2009;14:024017.

18. Keilhauer CN, Delori FC. Near-infrared autofluorescence imaging of the fundus: Visualization of ocular melanin. Invest Ophthalmol Vis Sci 2006;47:3556-64.

19. Thomas G, McWade MA, Paras C, et al. Developing a clinical prototype to guide surgeons for intraoperative label-free identification of parathyroid glands in real time. Thyroid 2018;28:1517-31. 
20. Serra C, Silveira L, Canudo A, et al. Parathyroid identification by autofluorescence - preliminary report on five cases of surgery for primary hyperparathyroidism. BMC Surg 2019;19:120.

21. Kim Y, Kim SW, Lee KD, et al. Real-time localization of the parathyroid gland in surgical field using Raspberry Pi during thyroidectomy: a preliminary report. Biomed Opt Express 2018;9:3391-8.

22. Vanderbilt U. FDA approves device based on Vanderbilt invention to ID parathyroid during head and neck surgeries [Internet]. engineering.vanderbilt.edu 2018 [cited 2019 Oct 10]. Available online: https://engineering. vanderbilt.edu/news/2018/fda-approves-device-based-onvanderbilt-invention-to-id-parathyroid-during-head-andneck-surgeries/

23. DiMarco A, Chotalia R, Bloxham R, et al. Autofluorescence in Parathyroidectomy: Signal Intensity Correlates with Serum Calcium and Parathyroid Hormone but Routine Clinical Use is Not Justified. World J Surg 2019;43:1532-7.

24. DiMarco A, Chotalia R, Bloxham R, et al. Does fluoroscopy prevent inadvertent parathyroidectomy in thyroid surgery? Ann R Coll Surg Engl 2019;101:508-13.

25. Yuan B, Chen N, Zhu Q. Emission and absorption properties of indocyanine green in Intralipid solution. J Biomed Opt 2004;9:497-503.

26. Alander JT, Kaartinen I, Laakso A, et al. A Review of indocyanine green fluorescent imaging in surgery. Int J Biomed Imaging 2012;2012:940585.

27. Jitpratoom P, Anuwong A. The use of ICG enhanced fluorescence for the evaluation of parathyroid gland preservation. Gland Surg 2017;6:579-86.

28. Vidal Fortuny J, Karenovics W, Triponez F, et al. IntraOperative Indocyanine Green Angiography of the Parathyroid Gland. World J Surg 2016;40:2378-81.

29. Vidal Fortuny J, Belfontali V, Sadowski SM, et al. Parathyroid gland angiography with indocyanine green fluorescence to predict parathyroid function after thyroid surgery. Br J Surg 2016;103:537-43.

30. Rudin AV, McKenzie TJ, Thompson GB, et al. Evaluation of Parathyroid Glands with Indocyanine Green Fluorescence Angiography After Thyroidectomy. World J Surg 2019; 43:1538-43.

31. Lang BHH, Wong CKH, Hung HT, et al. Indocyanine green fluorescence angiography for quantitative evaluation of in situ parathyroid gland perfusion and function after total thyroidectomy. Surgery 2017;161:87-95.

32. Vidal Fortuny J, Sadowski SM, Belfontali V, et al.
Randomized clinical trial of intraoperative parathyroid gland angiography with indocyanine green fluorescence predicting parathyroid function after thyroid surgery. Br J Surg 2018;105:350-7.

33. Kose E, Rudin A, Kahramangil B, et al. Autofluorescence imaging of parathyroid glands: An assessment of potential indications. Surgery 2020;167:173-9.

34. Thomas G, McWade MA, Nguyen JQ, et al. Innovative surgical guidance for label-free real-time parathyroid identification. Surgery 2019;165:114-23.

35. Thomas G, Squires M, Metcalf T, et al. Imaging or a Fiber Probe-based Approach? Assessing Different Methods to Detect Near Infrared Autofluorescence for Intraoperative Parathyroid Identification. J Am Coll Surg 2019;229:596-608.e3.

36. Kahramangil B, Dip F, Benmiloud F, et al. Detection of Parathyroid Autofluorescence Using Near-Infrared Imaging: A Multicenter Analysis of Concordance Between Different Surgeons. Ann Surg Oncol 2018;25:957-62.

37. Kahramangil B, Berber E. Comparison of indocyanine green fluorescence and parathyroid autofluorescence imaging in the identification of parathyroid glands during thyroidectomy. Gland Surg 2017;6:644-8.

38. Kim SW, Lee HS, Ahn YC, et al. Near-Infrared Autofluorescence Image-Guided Parathyroid Gland Mapping in Thyroidectomy. J Am Coll Surg 2018;226:165-72.

39. Benmiloud F, Rebaudet S, Varoquaux A, et al. Impact of autofluorescence-based identification of parathyroids during total thyroidectomy on postoperative hypocalcemia: a before and after controlled study. Surgery 2018;163:23-30.

40. Ladurner R, Al Arabi N, Guendogar U, et al. Nearinfrared autofluorescence imaging to detect parathyroid glands in thyroid surgery. Ann R Coll Surg Engl 2018;100:33-6.

41. Kim SW, Song SH, Lee HS, et al. Intraoperative realtime localization of normal parathyroid glands with autofluorescence imaging. J Clin Endocrinol Metab 2016;101:4646-52.

42. McWade MA, Sanders ME, Broome JT, et al. Establishing the clinical utility of autofluorescence spectroscopy for parathyroid detection. Surgery 2016;159:193-202.

43. Büttner M, Musholt TJ, Singer S. Quality of life in patients with hypoparathyroidism receiving standard treatment: a systematic review. Endocrine. 2017;58:14-20.

44. Almquist M, Ivarsson K, Nordenstrom E, et al. Mortality in patients with permanent hypoparathyroidism after total thyroidectomy. Br J Surg 2018;105:1313-8.

45. Page C, Strunski V. Parathyroid risk in total thyroidectomy 
for bilateral, benign, multinodular goitre: report of 351 surgical cases. J Laryngol Otol 2007;121:237-41.

46. Serpell JW, Phan D. Safety of total thyroidectomy. ANZ J Surg 2007;77:15-9.

Cite this article as: Di Marco AN, Palazzo FF. Near-infrared autofluorescence in thyroid and parathyroid surgery. Gland Surg 2020;9(Suppl 2):S136-S146. doi: 10.21037/gs.2020.01.04
47. Squires M, Shirley L, Shen C, et al. Intraoperative Autofluorescence Parathyroid Identification in Patients With Multiple Endocrine Neoplasia Type 1. JAMA Otolaryngol Neck Surg 2019. [Epub ahead of print]. 